\title{
A Cadeirologia e o Mito da Postura Correta
}

Ada `vila Assunção'

\author{
The Mith of Correct Posture
}

'Professora do Departamento de Medicina Preventiva e Social da Faculdade de Medicina da Universidade Federal de Minas Gerais. Mestre e Doutora em Ergonomia pelo Laboratório de Ergonomia Fisiológica e Cognitiva da École Pratique des Hautes Études (Paris - França)
O artigo contesta a abordagem tradicional sobre as posturas adotadas pelos trabalhadores durante a realização de suas tarefas, a qual procura identificar e prescrever a postura correta sem considerar a ação humana durante o cumprimento dos objetivos da produção. Descrevendo os resultados de um estudo ergonômico realizado no setor de caixas de um hipermercado, apontam-se os limites da análise que desconsidera a dinâmica do arranjo das partes do corpo em situação real de trabalho. Ao final, são apresentadas as vantagens e as desvantagens das posturas sentada e em pé.

Palavras-chave: saúde do trabalhador, ergonomia, postura, em pé, sentado.

This study confronts the traditional approach to postures adopted by workers during the performance of their tasks, which attempts to identify and prescribe the correct posture without considering human action during the fulfillment of production aims. Describing the results of an ergonomic study of supermarket cashiers, the author illustrates the limitations of an analysis that ignores the dynamics of the arrangement of the parts of the body in real work situations. In the end, the advantages and disadvantages of seated and standing postures are given.

Keywords: worker health, ergonomics, posture, standing, seated. 


\section{Introdução}

Freqüentemente, os estudos dos postos de trabalho recomendam uma cadeira e uma estratégia de formação que visam conscientizar o trabalhador a respeito da postura mais correta a ser adotada. Os achados de literatura e as situações analisadas nos estudos citados ao longo deste artigo permitem criticar o referido modelo de intervenção, que prescreve cadeiras e posturas corretas como única alternativa de solução para os problemas identificados.

Será apresentado um modelo de análise que tenta compreender as razões que levam os trabalhadores a adotar posturas estereotipadas mesmo conhecendo as necessidades de seu corpo ou conscientes dos efeitos do comportamento postural adotado.

A abordagem da cadeira, aqui denominada cadeirologia, reduz o conceito de postura ao desconsiderar a dinâmica do aparelho músculo-esquelético e ao desprezar as outras funções do organismo implicadas na fisiologia postural, como a função visual, a mecânica circulatória, a posição dos órgãos internos, o sistema neurológico.

Sustentando-se em um modelo reducionista de ser humano, ou seja, o homem-máquina, a cadeirologia elabora recomendações para concepção do mobiliário incompatíveis com as possibilidades do corpo humano. A incompatibilidade gera conflitos entre os aparatos oferecidos pelo mobiliário e a utilização real que o trabalhador faz deles. Não é incomum verificar os funcionários de um banco, por exemplo, dispensarem a oferta de conforto de um certo aparato do posto de trabalho, finamente detalhado, mas que não possui qualquer serventia prática. É emblemático o caso de um bancário que não utiliza o encosto para o dorso para evitar o distanciamento do guichê e, assim, manter a vigilância ao seu entorno e à gaveta que comporta o numerário. Afinal, o risco de assalto é um dos principais problemas vivenciados nas agências bancárias.

Sob a mesma lógica, o funcionário de uma grande cadeia de hipermercado não consegue utilizar o assento em seu exíguo espaço de trabalho. A gerência opta por retirar os assentos e a trabalhadora não discorda, pois não poderia assentar-se e, ao mesmo tempo, manipular o teclado colocado em uma superfície acima do plano de trabalho princi- pal por onde as mercadorias são trasladadas, como se verá mais adiante.

Para tratar uma demanda, o trabalhador mobiliza as informações sobre as características do serviço solicitado que estão estocadas em sua memória, avalia o humor do cliente, prepara uma estratégia para abordálo, adota uma certa postura, ou seja, arranja os seus segmentos corporais no contexto de um dado ambiente térmico, sonoro e luminoso. Uma abordagem reduzida da situação do trabalho contentar-se-ia em avaliar as dimensões antropométricas, desconsiderando o uso que o funcionário faz do seu mobiliário.

Laville (1968) mostrou que na indústria microeletrônica a rigidez das posturas aumenta com as dificuldades surgidas ao longo do desenvolvimento da atividade, bem como são associadas à velocidade imposta pela esteira. Na situação estudada pelo autor, a necessidade de tratar sinais durante a realização das tarefas conduz à seguinte postura: o tronco aproxima-se da bancada para permitir uma boa distância olho-objeto, cujo foco visual depende da imobilização cervical, explicando, assim, a hipercontração dos músculos da região. São exemplos que ilustram a importância em se considerar o conjunto das exigências da tarefa e não apenas a contração muscular, como se ela fosse um resultado direto do comportamento estressado do trabalhador, independentemente da flutuação dos fatores de produção em um ambiente organizacional rígido.

O estudo de Assunção \& Lima (2000) em uma fábrica de jóias ilustra o caráter multifatorial da determinação da postura. Além de repetitivas, as tarefas realizadas solicitam habilidade e destreza manual, movimentos firmes e precisos. Para além da repetição, a precisão dos movimentos realizados na região distal dos membros superiores impõe uma carga estática à musculatura da região proximal e solicita, assim, o conjunto do aparelho músculo-esquelético dos membros superiores. Nota-se a exigência de responsabilidade e atenção no desenrolar das atividades de trabalho, o que conduz a um aumento da contração muscular estática, a qual, por sua vez, pode contribuir para a sobrecarga muscular global. Ou seja, os resultados obtidos mostram que o trabalho, apesar de repetitivo, não é essencialmente manual. Ele também exige concentração, atenção e 
responsabilidade, e todas essas exigências estão certamente determinando as posturas, principalmente as estáticas.

Além disso, as tarefas são realizadas sob pressão temporal e os erros são temidos, pois acarretam desperdícios de matéria-prima. A pressão temporal e o medo de errar podem aumentar a atividade muscular (Bongers et al., 2002).

Os resultados acima e a análise da situação do caixa de hipermercado, que será apresentada neste artigo, reforçam os pressupostos da Ergonomia sobre a multideterminação da postura adotada e o caráter global dos gestos humanos. Os dois pressupostos são apresentados a seguir.

\section{Qual modelo de ser hu- mano orienta as análises da Ergonomia?}

Quando se pretende estudar os aspectos humanos e técnicos ligados à realização do trabalho, a Ergonomia propõe-se a avaliar as competências para realizar a tarefa e a sua variabilidade. As pesquisas mostram que, conhecendo as exigências do trabalho, os traços da atividade do operador poderão ser estudados e certos elementos da situação poderão ser rearranjados para se obter o conforto para um trabalhador em particular.

A atividade visual, por exemplo, varia em função da claridade e da curva de adaptação do olho ao escuro. Tais características não são absolutamente idênticas em todos os indivíduos. As diferenças podem ter origens diversas: constitucionais, culturais, de formação etc. Entretanto, os indivíduos contornam as dificuldades. Os daltônicos, por exemplo, às vezes, descobrem tarde que portam deficiência, pois orientam-se menos pelas cores do que pelos traços das luzes, ou seja, eles mobilizam as outras habilidades que atenuam os efeitos das deficiências.

A Ergonomia leva em conta a ação do indivíduo mobilizada pela inteligência e pela experiência, descartando o modelo mecânico do ser humano em situação de trabalho. Para a Ergonomia, o funcionamento do homem em situação de trabalho não pode ser comparado a um modelo mecânico do tipo transformação de energia ou a um modelo informatizado de tratamento de dados.
A voz do ser humano não é um microfone, os seus ouvidos não são amplificadores, os seus olhos não são holofotes, as suas articulações não são polias, (Laville, 1977). O trabalhador muda de postura para solicitar a musculatura que estava em repouso, seleciona as imagens que são importantes para decidir, privilegia os ruídos indicadores do funcionamento da máquina... O ser humano não pode ser comparado a uma máquina. A máquina não tem uma idéia do mundo que a rodeia. O ser humano tem uma idéia e modifica esta idéia à medida que o mundo se transforma pela sua ação. Não seria esta característica a força do processo civilizatório humano?

Os conhecimentos sobre as características psicofisiológicas do ser humano em situação real de trabalho permitem afirmar que existe uma importante variabilidade inter e intraindividual e que em toda atividade profissional existe uma atividade mental. Além disso, a regulação individual e coletiva exerce um papel importante na realização da produção.

No setor da alimentação coletiva, uma distribuição informal dos trabalhadores nos postos do restaurante visa estabelecer um "compromisso" entre os objetivos da produção, as exigências das tarefas com forte componente físico e as deficiências músculo-esqueléticas de um grupo de cozinheiras. A margem de liberdade existente permite que os objetivos da produção sejam atingidos e que os indivíduos que estejam sofrendo de dores e da diminuição da força muscular possam continuar trabalhando (Assunção, 1998; 2003).

As regras e as normas de produção coerentes com os objetivos de rentabilidade econômica assentam-se numa noção artificial de um trabalhador jovem, do sexo masculino, em boa saúde, com os receptores sensoriais intactos e resistentes aos riscos presentes, imutáveis ao longo do tempo e opacos às agressões presentes nos ambientes nocivos (Wisner \& Marcelin, 1971). Nem sempre as normas de produção consideram o saberfazer construído ao longo do tempo em que o trabalhador depara-se com as situações reais de trabalho. Desconsiderando a variabilidade humana, tais normas são incoerentes e desumanizam o trabalho (Lima, 2001).

Quando os projetistas das situações de trabalho tentam reduzir o papel do trabalha- 
dor, considerando-o análogo aos sistemas técnicos, quando eles uniformizam as exigências de trabalho, normatizam os procedimentos, estabelecem regras rígidas de tempo, não podem prever o conflito provável, explícito ou não, entre as características dos trabalhadores e o sistema de produção (Abrahão, 2000).

No plano cognitivo, a Psicologia traz conhecimentos sobre certos mecanismos de funcionamento do indivíduo; por exemplo, como ele leva em conta as novas informações para modificar as suas representações mentais, quais são as propriedades dessas representações, como elas se constituem (Wisner, 1987). Em relação ao conteúdo cognitivo da tarefa, o principal aspecto a ser considerado é a tomada de decisões. No entanto, é conveniente abordar as dificuldades em perceber os sinais quando o trabalhador está cansado ou em situações de desconforto luminoso ou térmico que perturbam a identificação e o reconhecimento da informação.

O sofrimento de fadiga psíquica pode estar presente nos casos em que, por exemplo, a falta de sono provocada pelos horários extremos do trabalho gera uma sobrecarga e pode explicar as alterações de humor ou deixar o indivíduo mais susceptível (estando mais cansado) aos riscos biomecânicos existentes no ambiente de trabalho.

Assim, de que adiantaria a implantação de uma cadeira de dimensões adequadas se a tensão provocada pelos desajustes da organização do ambiente de trabalho provoca hipercontração da musculatura dorsal e cervical?

A Biomecânica é a disciplina que estuda as forças estáticas e dinâmicas que agem sobre o corpo e que pode contribuir fortemente para a concepção dos espaços de trabalho. No entanto, articular à avaliação biomecânica a análise das outras dimensões humanas já citadas pode contribuir para evitar uma abordagem reduzida do trabalhador, a qual expli$\mathrm{ca}$, em muitos casos, entre outros fatores, o insucesso do mobiliário implantado.

\section{Qual Biomecânica? A di- nâmica do corpo e o mito da postura correta}

O aumento de Lesões por Esforços Repetitivos no mundo todo (EASHW, 2000) conduz à hipótese de que as exigências biomecânicas provocam reações severas no organismo e, assim, de maneira geral, elas são superiores às capacidades funcionais individuais.

As pressões exercidas sobre os tecidos moles podem provocar reações dos tecidos envolvidos. Geralmente, e de maneira bem resumida, as reações são: a) mecânicas e fisiológicas - variações do comprimento, do volume, rupturas; b) fisiopatológicas - mudança na concentração iônica das células dos músculos, evolução das características do potencial de ação do músculo, insuficiência crônica do líquido sinovial, rupturas das fibras de colágeno do tecido do tendão, hipertrofia do epineuro, perturbando o potencial de ação nas fibras nervosas, com conseqüentes alterações motoras e sensitivas (Assunção, $\mathrm{s} / \mathrm{d})$.

Os conhecimentos da disciplina citada são úteis e indispensáveis para abordar as posturas no trabalho e orientar a concepção dos postos, mas são insuficientes. Algumas análises focalizadas na Biomecânica desconsideram o caráter dinâmico do corpo e deixam margens para construir o mito da postura correta.

O esqueleto humano pode ser comparado a um conjunto de três peças empilhadas umas sobre as outras: a cabeça, o tórax e a bacia. As formas e as dimensões das peças são diferentes entre si. Mesmo assim, elas conseguem se manter empilhadas na posição vertical graças a um minucioso e intenso trabalho do conjunto do corpo.

Para se obter um arranjo estável das três peças, é necessário colocar o centro de gravidade de uma peça sobre o centro de gravidade de sua vizinha de baixo, o que solicita um perfeito alinhamento vertical dos centros de gravidade para evitar uma tensão sobre o invólucro do conjunto, que é formado pelos tecidos moles que compõem o aparelho músculo-esquelético.

O alinhamento é obtido por meio de mecanismos finos, pois, como lembra Bienfait (1993), "cada gesto é feito de um conjunto de ações que se complementam para atingir o objetivo final". Uma tensão inicial provoca uma sucessão de tensões isoladas. Todos os gestos humanos são globais e recrutam, nos dizeres do autor, o conjunto do sistema locomotor. 
De maneira bastante didática, Bienfait explicita as duas grandes funções do sistema locomotor: a deambulação e a preensão. A primeira é uma função ascendente que parte da cintura pélvica e dos membros inferiores; a segunda é uma função descendente que parte da cintura escapular e dos membros superiores. Os conhecimentos da fisioterapia são ainda mais elucidativos e podem contribuir para o entendimento do ser humano em situação de trabalho quando afirmam que, em cada função, os movimentos das duas cinturas são ligados por dois sistemas cruzados. Ou seja, na deambulação, a cintura escapular equilibra a cintura pélvica, que projeta o membro inferior. Na preensão, ocorre o inverso, pois a cintura pélvica serve de ponto de apoio para os movimentos do tronco e da cintura escapular, que dirigem o membro superior.

A noção de dois sistemas cruzados que se equilibram entre si esclarece sobre o caráter dinâmico do gestual humano, que, por sua vez, fragiliza os argumentos que sustentam a prescrição de uma postura ideal supostamente fixa no tempo e no espaço. Ora, mórbido seria o corpo congelado. Então, como prescrever a postura correta?

\section{Qual é a melhor postura?}

Postura é o arranjo relativo das partes do corpo. A postura é o principal elemento da atividade do ser humano, ou seja, não se trata apenas de manter-se em pé ou sentado, mas de "agir" dando um suporte à tomada de informações e à ação motora no meio de trabalho. Vista dessa forma, a postura é um meio para localizar as informações exteriores e preparar os segmentos corporais e os músculos a fim de agir no ambiente. Tratase, assim, de organizar o espaço em referência ao seu corpo para localizar-se, deslocarse e agir numa perspectiva dinâmica.

A postura é um meio de expressão e comunicação, é um sinal da condição sociocultural do indivíduo e, assim, meio de expressão da condição no grupo. Se não, como explicar os braços cerrados e presos para trás dos trabalhadores humildes que, por vezes, abaixam as suas cabeças para ouvir a sua hierarquia? Por fim, e não menos importante, uma das funções da postura é proteger as estruturas de suporte do corpo contra lesão ou deformidade progressiva, independentemente da atitude (ereta, deitada, agachada, encurvada) nas quais essas estruturas estão trabalhando ou repousando (Kendall, 1995).

A postura saudável seria o estado de equilíbrio muscular e esquelético no qual os músculos funcionam mais eficientemente e posições ideais são proporcionadas para acomodar os órgãos torácicos e abdominais.

A postura estereotipada é uma relação defeituosa entre as várias partes do corpo. Por exemplo, os punhos hiperfletidos ou hiperextendidos podem levar à compressão dos nervos periféricos aí localizados (Claudon, 1995). Das definições propostas, denota-se que, certamente, determinadas posturas devem ser evitadas pelo risco que elas podem trazer para o equilíbrio do corpo.

Porém, os conhecimentos mencionados não autorizam a culpar o trabalhador que, em tese, assumiria a postura estereotipada por não ter consciência da postura saudável.

Os efeitos são estudados pelos estudos epidemiológicos que nos últimos vinte anos buscaram identificar os fatores de riscos para o adoecimento músculo-esquelético em populações de trabalhadores. Alguns resultados são elucidativos.

Em estudo de laboratório, Hagberg (1981) provocou tendinite aguda em mulheres que realizavam elevações repetidas dos ombros durante uma hora de observação. Outros autores sugerem que as associações entre tendinite e trabalho com os braços elevados podem ser relacionadas com a repetitividade das extremidades dos membros superiores enquanto os ombros e os braços permanecem sob força muscular estática a fim de garantir a estabilidade dos membros superiores suspensos e sem apoio (Winkel \& Westgaard, 1992).

Entre trabalhadores de uma linha de montagem expostos a elevações repetitivas dos braços e obrigados a sustentá-los durante longos períodos da jornada de trabalho, foi comum a descoberta de dor à palpação do músculo trapézio entre aqueles que se queixavam de dores nos ombros. Em outro estudo transversal, as mulheres que executaram flexões repetitivas dos ombros apresentaram dor e sensibilidade temporária à palpação do ombro. Nesse estudo, a exposição consistia em flexões repetitivas dos ombros num ângulo que variava de 0 a 90 graus e a 
uma cadência de 15 flexões por minuto (Bielle, 1981).

Os resultados de uma pesquisa evidenciam que os estudantes avaliados contraíram uma tendinite temporária quando submetidos a flexões repetidas dos ombros. Pode-se lembrar também da exposição dos fatores de hipersolicitação das estruturas músculo-esqueléticas em casos de atividades esportivas. Os nadadores de competição que executam movimentos repetitivos dos braços acima da cabeça apresentam a síndrome dolorosa do ombro. Dez por cento dos lançadores já apresentaram um episódio de tendinite. Numa pesquisa que entrevistou 2496 nadadores, $15 \%$ declarou apresentar uma incapacidade importante do ombro como conseqüência de uma síndrome dolorosa.

Enfim, a postura é responsável pela manutenção dos segmentos corporais no espaço, fundamental para se lutar contra a gravidade e depende das características biomecânicas do corpo humano, das informações internas e extereoceptivas (musculares, articulares, labirínticas, visuais, auditivas), das estruturas nervosas de integração e de comando dos músculos antigravidade e das atividades desses músculos.

A análise da postura adotada no trabalho implica identificar os seus determinantes, como afirma Lima (2000): "a postura assumida por um trabalhador nunca é somente o resultado de idiossincrasias pessoais, mas é determinada pela inter-relação complexa dos múltiplos fatores constituintes da situação de trabalho". Para tal, recomenda-se avaliar o espaço onde o corpo está agindo, os equipamentos, os instrumentos e os objetos manipulados, a variabilidade do estado do trabalhador: ele está cansado, mais velho, é novato, ela está grávida? Esses aspectos não são abordados pela cadeirologia.

\section{Métodos e procedimentos}

A partir da demanda inicial que colocou o problema da melhor postura de trabalhoem pé ou sentado - , os resultados das análises realizadas serviram de base para esclarecer e propor as medidas de melhoria dos postos de caixa em um hipermercado. Alguns aspectos foram aprofundados com o objetivo de melhor compreender o contexto em que se insere o trabalho, ou seja, a tecnologia e a organização.
Realizaram-se entrevistas abertas, registros das verbalizações espontâneas dos trabalhadores durante as observações, levantamento das opiniões dos usuários, estudo do volume da produção, observações abertas e observações sistemáticas com a ajuda de cronômetro e câmera de vídeo. Durante as observações diretas, foram realizadas entrevistas simultâneas, tendo como objetivo esclarecer pontos específicos.

As observações do trabalho tiveram o objetivo de analisar as diferentes zonas de trabalho das recepcionistas, tais como: leitora ótica, teclado, impressora de cheques e de tickets de cartão de crédito, caixa anti-roubo, gaveta para o numerário, retira-metais, armazenamento de sacos para embalagem etc. Estudou-se a utilização do espaço de trabalho disponível. Procedeu-se a uma análise dos gestos efetuados e das posturas adotadas, contextualizando-os. Avaliaram-se as habilidades mobilizadas durante o relacionamento com o público e, finalmente, as estratégias para cumprimento dos objetivos globais do trabalho.

Foram escolhidos dias diferentes para as filmagens, respeitando-se, ao máximo possível, as variações de fluxo de clientes no hipermercado. Dessa forma, foram filmadas várias situações. Importante é lembrar a recusa, aceita de pronto pelos pesquisadores, de algumas recepcionistas em serem filmadas sob a alegação de um certo nervosismo em tais situações.

Neste artigo, serão apresentados os resultados de 45 minutos de observação registrados pela filmadora, entre $19 \mathrm{~h}$ e $19 \mathrm{~h} 45$, num dia considerado de grande movimento (sexta-feira), e os resultados das observações realizadas durante o atendimento de dois clientes por uma segunda recepcionista, num horário de menor movimento $(12 \mathrm{~h} 30$ a 13h30 de um sábado).

As entrevistas foram realizadas nos momentos de ausência de clientes, principalmente no início da manhã. No entanto, durante as observações diretas, foram realizadas entrevistas simultâneas para esclarecimento de pontos específicos levantados durante as observações.

Foram criadas as seguintes variáveis para a observação direta: escanear, escanear e multiplicar, digitar o código da etiqueta, acionar e limpar a esteira, preparar o saco plástico e entregá-lo ao cliente, ensacar. As va- 
riáveis correspondem às operações da fase de tratamento do artigo. Na outra fase do trabalho da recepcionista no atendimento a cada cliente, fase comercial, as variáveis observadas foram: verificar documentos do cliente, imprimir cheque e recibo, entregar os documentos ao cliente.

O programa Kronos ajudou no tratamento dos dados. Assim, as operações foram decodificadas em um protocolo de observação que objetivou também identificar os períodos de posturas em pé e sentada em relação com as operações realizadas. O programa Kronos, que foi alimentado com dados extraídos da crônica da atividade após a escolha das variáveis citadas de acordo com as hipóteses elaboradas durante as observações abertas, possibilitou reconstituir a organização temporal da atividade e apresentá-la em forma de gráficos. Esse tratamento de dados permite, igualmente, colocar em evidência a seqüência das operações, bem como a sua variabilidade.

Por meio da análise das filmagens, foi realizado um estudo detalhado dos gestos e movimentos adotados pelos trabalhadores, relacionando-os com as operações anteriormente avaliadas.

\section{Resultados: o caso da caixa de hipermercado}

A análise das operações e dos movimentos que as acompanham colocam em evidência o caráter repetitivo da tarefa, pois a trabaIhadora executa a mesma operação, adotando a mesma postura. Porém, ela varia $25 \%$ no caso da recepcionista 1 e 3\% para a recepcionista 2 , de acordo com a quantidade de produtos semelhantes a serem digitados, com o volume e o peso, e com o desenrolar da jornada de trabalho.

A amplitude dos movimentos da recepcionista varia de acordo com o tamanho, o peso e a posição do produto sobre a esteira: pega o artigo com a mão esquerda, transfere o artigo de mão, passa o artigo com a mão direita na leitora, com a mão esquerda vai pegar outro artigo, enquanto a mão direita deposita o artigo registrado na esteira dois.

De acordo com o sentido ou a direção do esforço - empurrar ou puxar a mercadoria, por exemplo - e com a sua freqüência, a exigência física varia muito. Uma carga muito intensa leva o trabalhador a adotar uma postura mais adaptada ao esforço que é prioritário na ação e, assim, o conforto postural previsto pode ser alterado para se atingir os objetivos da ação. As torções e as flexões do corpo são influenciadas pela incompatibilidade entre as dimensões dos elementos do trabalho e as dimensões do trabalhador.

Observou-se, por exemplo, uma recepcionista registrar as mercadorias na posição sentada, mas apoiando os quadris sobre os bordos da cadeira, sem poder apoiar o dorso, já que teria de alcançar o teclado.

No entanto, em algumas situações em que o ciclo fundamental se modifica, a postura o acompanha. São momentos caracterizados pelo tipo de mercadoria a ser registrado ou então pelo momento da evolução da esteira.

Desta forma, na maioria das situações, a postura é o resultado das exigências visuais e cognitivas, bem como do mobiliário. Por exemplo: se o plano de trabalho é mais largo do que o comprimento do tronco, como é o caso da esteira por onde os produtos são registrados, e se o trabalhador procura, de acordo com os objetivos preestabelecidos, vigiar o carrinho de compras do cliente, ele se colocará nas pontas dos pés, curvando o tronco sobre a esteira para garantir a visualização do conteúdo do carrinho.

As mercadorias registradas têm forma e peso diferentes. Manipulá-las implica solicitar diferentes grupos musculares. Observouse, por exemplo, que a recepcionista sempre se levanta, se estiver sentada, quando ela vai registrar uma mercadoria pesada. De maneira geral, os artigos registrados serão depositados na segunda esteira, aguardando 0 ensacamento. Observam-se estratégias para ensacar em seguida ao registro, nos casos de artigos pesados - caixa de cervejas em lata, pacote de cinco quilos de arroz - , já que o produto é erguido para ser passado sobre a leitora, aproveitando-se para ganhar tempo ensacando-o imediatamente.

Alguns artigos como roupas, revistas, CDs, ovos, por exemplo, também são ensacados imediatamente após o registro. Na maioria das vezes, a recepcionista preocupa-se em fazer uma triagem dos produtos a serem ensacados. Outra estratégia é ajuntar artigos gelados ou congelados para acelerar e garantir as boas condições de transporte. 
A recepcionista controla o número de sacos de embalagem fornecidos, retirando e fornecendo paulatinamente ao cliente. A distribuição dos sacos plásticos é custosa do ponto de vista postural, obrigando a flexão anterior do tronco. Nem sempre os sacos são facilmente manipuláveis: acontece de não estarem perfeitamente perfurados ou de estarem colocados um no outro.

O ensacamento do produto multiplica o número de fontes de informações a serem consideradas pela recepcionista. Assim, ela deverá olhar o carrinho que está sendo esvaziado e os pacotes que estão sendo depositados sobre a esteira e, ainda, a evacuação dos produtos registrados para evitar aglomeração.

Nota-se que é freqüente a manipulação do teclado, pois nem sempre existem as etiquetas, ou pode acontecer de estarem ilegíveis. A localização do teclado obriga o trabalho do membro superior direito em extensão sem apoio possível do cotovelo.

As recepcionistas adotam a estratégia de ler atentamente o valor que aparece na tela do scanner. Elas dizem, a este propósito, que o erro tem que ser controlado e que o sinal sonoro, emitido a cada vez que o artigo é lido, não é suficiente para a certeza de que o produto foi registrado. É imperativo controlar se aparece, a quantidade de vezes em que aparece e se não há erro entre o valor impresso e o valor real. Pode-se afirmar que o trabalho de caixa de hipermercado não é um trabalho manual. Ao contrário, existe uma forte solicitação das funções mentais.

O teclado é situado acima do scanner, localização que implica a adoção de uma postura de flexão do tronco para frente para permitir o seu alcance. Nem sempre a distância de $53 \mathrm{~cm}$ fica na zona de alcance da recepcionista, dificultando ou mesmo impossibilitando a adoção da postura sentada, dependendo das dimensões dos segmentos corporais superiores da recepcionista. As Figuras 1 e 2 mostram que a recepcionista assenta-se na fase de relação comercial (verifica documento, imprime recibo, entrega documento), quando não está escaneando, pois nesse momento não precisa ver o visor nem tocar o teclado ou solicitar a musculatura do dorso para ajudar no levantamento do peso. Contudo, ocorre de a recepcionista não se assentar nem na fase comercial, como ilustra a Figura 3. Que outros fatores estariam determinando a postura em pé ou sentada?

Figura 1 Sequiência das operações realizadas e a postura adotada (sentada ov em pé) pela recepcionista 1, observada durante 45 minutos.

Período considerado de muito movimento.

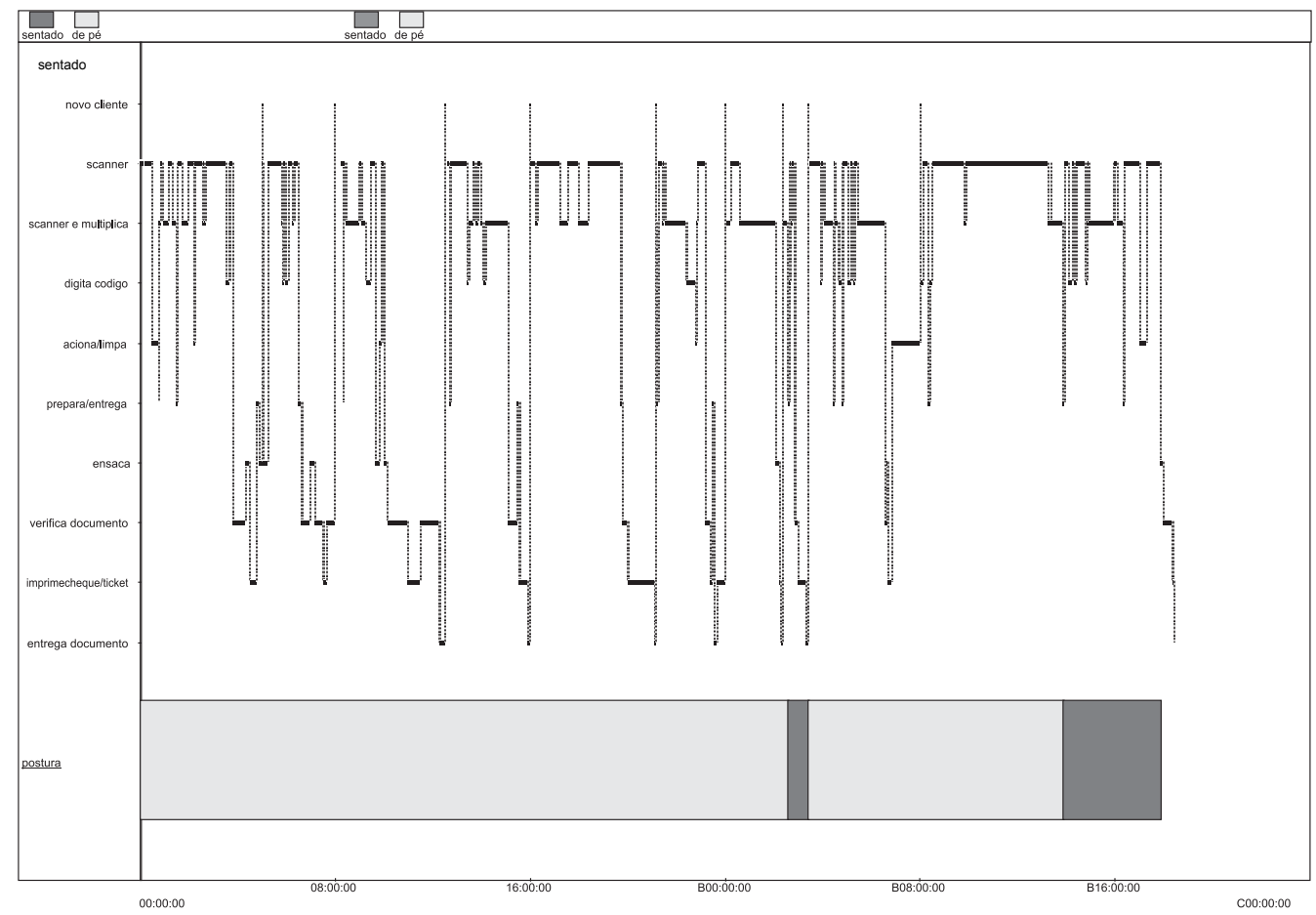


Figura 2 Seqüência das operações realizadas e a postura adotada (sentada ou em pé) pela recepcionista 2 no atendimento ao cliente 1 .

Período considerado de pouco movimento.

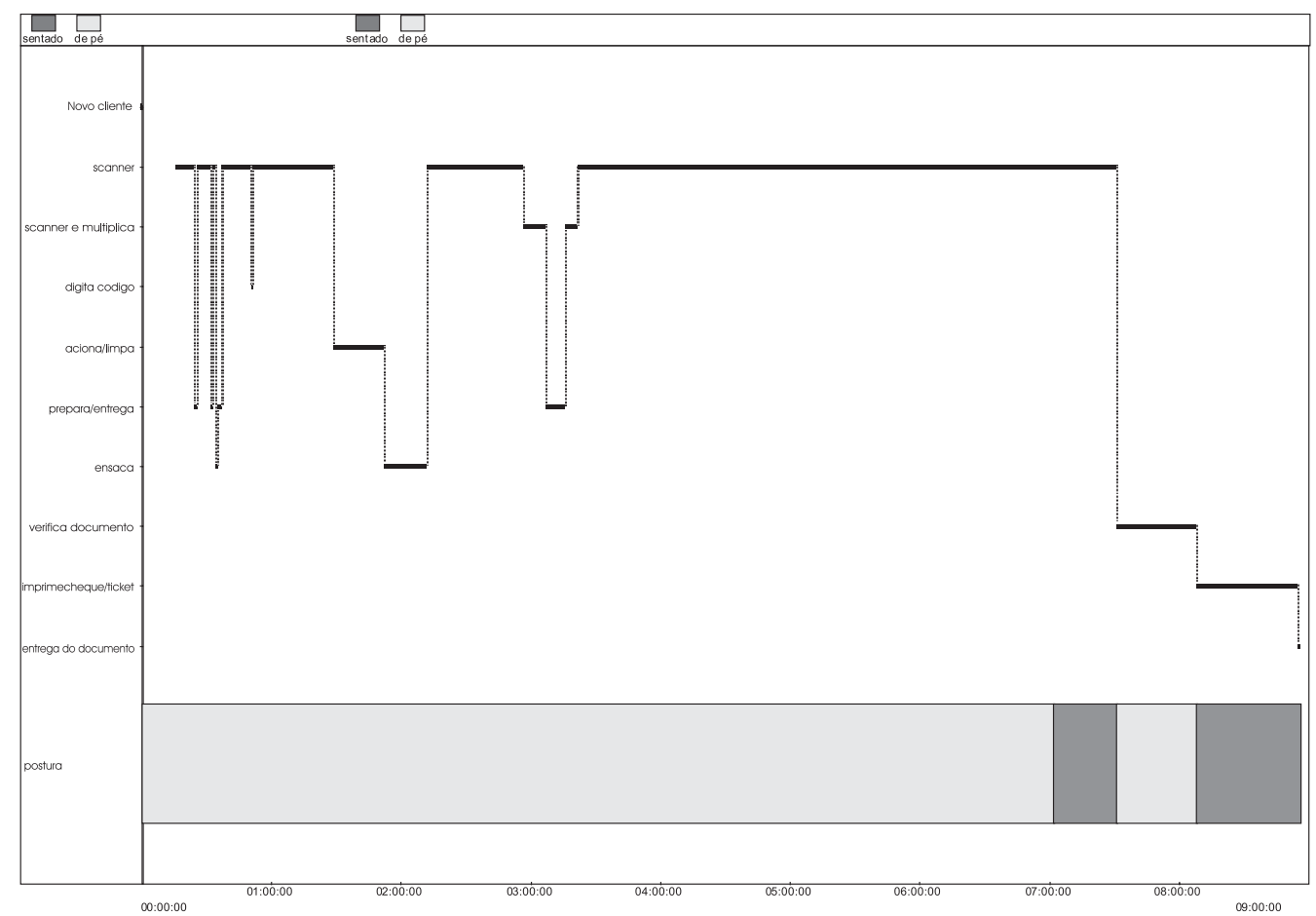

Figura 3 Sequiência das operações realizadas e postura adotada (sentada ou em pé) pela recepcionista 2 no atendimento ao cliente 2 .

Período considerado de pouco movimento.

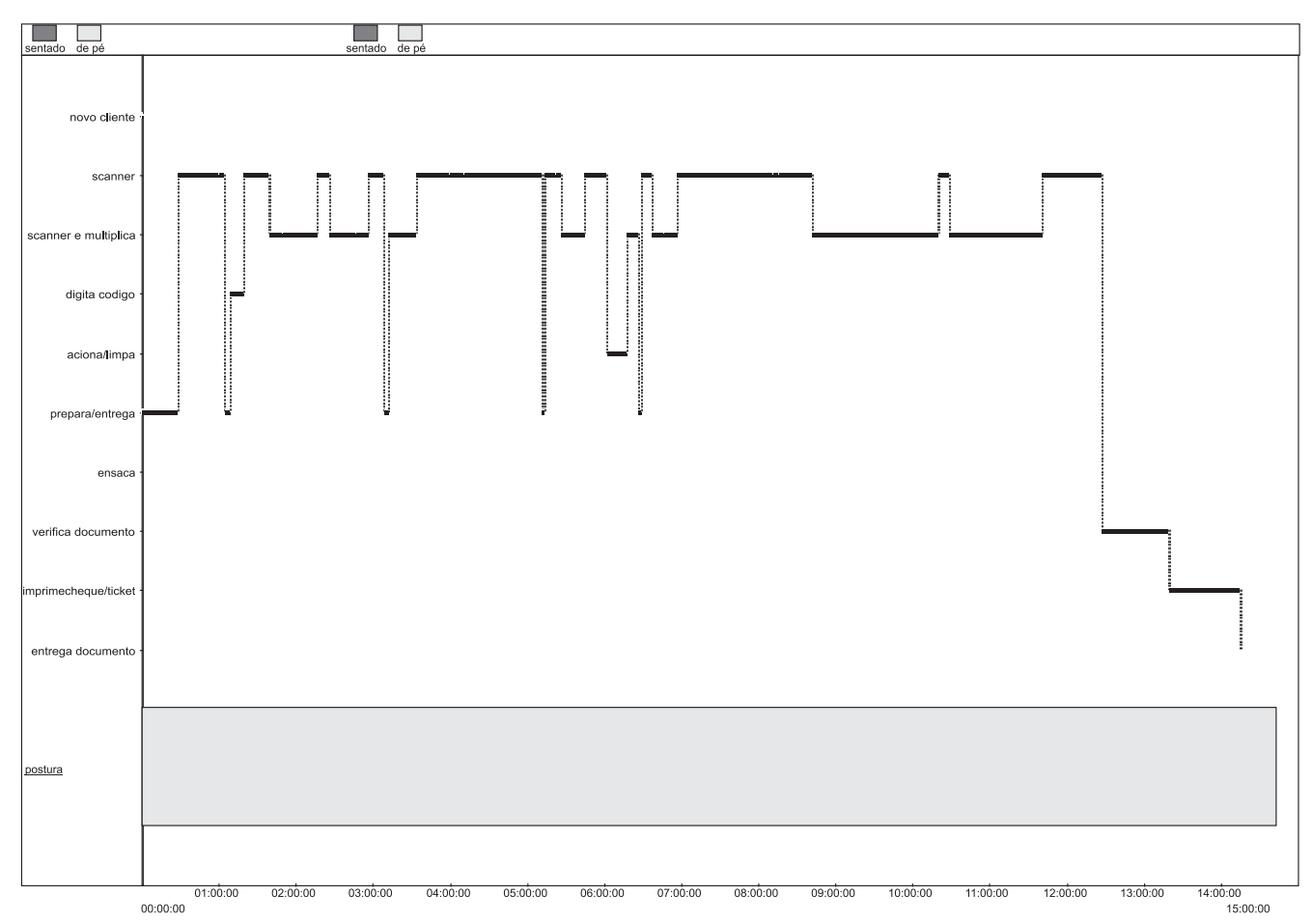


A recepcionista é obrigada a contar as unidades para, em seguida, registrar (digitando ou escaneando, se o produto permitir) e, na seqüência, digitar a cifra correspondente ao número de produtos desejados pelo cliente.

O modo operatório depende da qualidade da etiqueta, já que alguns produtos acondicionados em caixa de papelão não são lidos imediatamente, talvez pela qualidade do papel. O mesmo acontece com revistas ou cadernos. Nesses casos, a recepcionista gira o produto várias vezes, tentando fazer a boa apresentação da etiqueta para a leitora. Os produtos frios apresentam, muitas vezes, umidificação das etiquetas, o que impossibilita a leitura ótica, obrigando a recepcionista a digitar o código.

A dimensão da esteira pode induzir as atitudes do cliente, levando este a entregar o produto diretamente à recepcionista ou então a empilhar vários produtos na tentativa de esvaziar o seu carrinho com a esperança de terminar logo. Isso pode trazer perturbações, como o fato de o produto cair ou então de a recepcionista ser obrigada a ser mais atenta para evitar que um produto seja dissimulado entre os outros.

A terceira esteira, situada no plano inferior às outras duas, nem sempre é utilizada. Ocorre freqüentemente uma aglomeração de produtos, levando a recepcionista a interromper o registro para ajudar ou esperar o cliente a esvaziar a segunda esteira. Essas atitudes são acompanhadas de uma extrema atenção para seguir o fluxo do cliente que deposita $\mathrm{e}$ do acompanhante que ensaca. No caso de o cliente não estar acompanhado, a recepcionista observa o estado da segunda esteira e pode ser levada a interromper o registro para proceder ao ensacamento.

Em momentos de menor fluxo de clientes, as recepcionistas, quase de maneira sistemática, embalam os produtos, cumprindo, assim, a meta de bem servir o cliente. Entretanto, em períodos mais acelerados, esta conduta é limitada.

As recepcionistas possuem estratégias de ajuntar produtos semelhantes, sendo que nestes casos passa apenas o primeiro sobre a leitora, registra o número de vezes para, a seguir, comandar a operação de multiplicar.

A atividade real do trabalho das recepcionistas sofre influências da política comercial, das características dos clientes, do ambiente, dos materiais e do espaço de trabalho. Alguns desses fatores interagem entre si, determinando imprevistos que serão regulados pelos funcionários. Os esforços físicos a serem exercidos compreendem tanto os esforços que contribuem para a transformação do produto - ação sobre os instrumentos, sobre os artigos, sobre os elementos a serem sustentados pelo corpo - quanto os esforços decorrentes das posturas adotadas.

Há conflitos: cliente que duvida da soma, cliente que reclama do produto que passou e que ele diz não ter colocado no carrinho, cliente que não aceita o engano cometido pelos outros setores ao etiquetar ou pesar 0 produto, cliente que não aceita a negativa do cartão do crédito... Essas são situações que geram um clima tenso e as recepcionistas, na medida do possível, tentam administrá-lo ou então chamam o coordenador de caixa.

Pode ocorrer de o coordenador levar a mercadoria até as prateleiras para verificar o verdadeiro preço, pois acontece de as etiquetas terem um valor diferente do apontado pela leitora ótica e visualizado no monitor pelo cliente.

A operadora movimenta constantemente a cabeça, dirigindo o olhar para diversos pontos, tentando selecionar as informações importantes que vão orientar a sua ação. Assim, para ela, é importante avaliar a situação do carrinho, verificar se ainda há espaço na esteira, estar atenta às semelhanças e às diferenças entre os produtos aparentemente idênticos, observar em detalhes as propriedades das mercadorias e o comportamento do cliente.

Desse modo, percebe-se que o trabalho das recepcionistas, apesar da existência de pequenos ciclos que se repetem, no caso do registro de artigos pelas características descritas, requer uma intensa atividade mental (Assunção \& Souza, 1999; Assunção, 2002).

\section{Discussão}

Os conhecimentos sobre a postura sentado-em pé são extraídos da fisiologia e da biomecânica. Estar de pé significa que todo o peso do corpo é suportado pelo pé e que as pessoas vão trabalhar contra a lei da gravidade. Vários músculos do dorso e das pernas são solicitados para manter a postura 
em pé. $O$ sistema cardiovascular trabalha igualmente contra a gravidade para fazer o sangue retornar dos membros inferiores em direção ao coração e, assim, favorecer a troca de nutrientes entre os tecidos. Se houver, como no caso das recepcionistas do caixa de hipermercado, uma postura estática, esta provocará uma diminuição das trocas nutricionais dos discos intervertebrais responsável pelos distúrbios osteomusculares que motivaram a demanda do estudo.

\section{Em pé, sentado ou sen- tado-em pé?}

Os resultados de uma revisão da literatura realizada por Messing (1998) e citada por Vézina \& Lajoie (1996) mostram que vários estudos epidemiológicos sugerem que os anos de trabalho passados em postura em pé imóvel poderiam causar problemas de circulação e problemas no aparelho músculoesquelético. Ryan (1989) realizou um estudo numa população de 513 trabalhadores de sete supermercados. Os resultados mostraram que os caixas permanecem $89,8 \%$ do tempo em pé, enquanto que os trabalhadores do depósito permaneciam $44,9 \%$ nesta mesma posição, e que há uma relação entre o tempo passado em pé e o número de problemas nas pernas e nas costas.

Diniz \& Ferreira Jr. (1993-1994) mostraram elevada prevalência de sintomas músculo-esqueléticos em 79 operadores de checkout em mercados de São Paulo que responderam a questionários anônimos: $77 \%$ deles referiram-se à dor em pelo menos uma região corporal durante a última semana de trabalho.

De acordo com Vézina \& Lajoie (1998), as conseqüências do trabalho estático em pé são as seguintes: aparecimento de varizes devido à pressão hidrostática nas veias das pernas, desenvolvimento de edema nos membros inferiores devido à diminuição da circulação linfática, sintomas de dor nos membros inferiores e na região lombar, sendo que o quadro doloroso nesta região é relacionado com o maior risco de ferimentos durante a manutenção de cargas.

Uma fadiga generalizada é possivelmente relacionada à carga cardiovascular e também ao trabalho muscular mais importante na postura em pé do que no caso da postura sentada.
No caso das recepcionistas do checkout, deve-se sublinhar que a solicitação muscular é importante, pois, em se tratando de um trabalho manual, rápido e de precisão, como mostram os resultados apresentados, há diminuição dos pontos de apoio necessários para manter a estabilidade do corpo. A cadeirologia negaria os fatores mencionados ao concentrar-se exclusivamente na procura de uma cadeira perfeita e na prescrição de uma postura ideal.

\section{Em pé}

A partir da posição ereta, o movimento voluntário da coluna em qualquer direção é iniciado pela contração concêntrica dos músculos responsáveis por essa ação.

Existe uma contração muscular isométrica quando o músculo não muda de comprimento durante a contração muscular: por exemplo, quando ele se mantém em uma postura ou quando a carga a ser deslocada é mais elevada que a força de tensão que o indivíduo desenvolve. Uma contração é isotônica quando a tensão que ela provoca é constante e o músculo encurta. O organismo humano acomoda-se mal à contração muscular isométrica prolongada, resultando em fadiga muscular. Se as situações de trabalho exigem uma rigidez máxima, os problemas acentuam-se.

Além da solicitação muscular, a postura ortostática solicita a ação dos discos intervertebrais. As pressões no disco intervertebral são mais elevadas nessa posição do que na posição deitada, mas usualmente menores do que na sentada. Quando em pé, as pessoas devem realizar esforços para compensar a força da gravidade. Isso é possível pela pressão dos discos intervertebrais, que mantêm os corpos separados, retesando os ligamentos longos e evitando o achatamento da coluna. No entanto, como apresentado anteriormente, pressões contínuas sobre o disco podem provocar degeneração do mesmo.

A posição em pé com o peso do corpo sendo suportado principalmente por uma das pernas, estando a outra relaxada, aumenta a atividade eletromiográfica ao nível da quinta vértebra lombar no lado da perna que suporta o peso (Dolan et al. 1988).

A posição em pé ideal não é usualmente mantida por longos períodos, pois as pessoas 
recorrem ao uso assimétrico das extremidades inferiores, usando alternadamente a perna direita e a esquerda como o principal apoio. Quando o peso do corpo apóia-se em um só membro inferior, a pelve eleva-se do lado oposto e uma concavidade lateral lombar surge nesse mesmo lado. A fim de compensar a referida inclinação lombar, a região toráxica forma uma concavidade do lado oposto e a cervical, por sua vez, fica côncava no mesmo lado do apoio.

É importante lembrar que o indivíduo, para se manter de pé, tem de se movimentar sobre a sua base de sustentação. As curvaturas não estão corretamente alinhadas devido à postura adotada - no caixa do hipermercado, por exemplo, a flexão anterior da coluna para melhor visualizar as informações registradas pela leitora ótica. Nesse caso, uma atividade bem maior sobre as áreas musculares é então requerida para manter a postura ereta. Nota-se, assim, uma contradição entre os objetivos do conforto postural e as exigências das tarefas.

Na posição em pé, a cintura pélvica é inclinada para a frente devido à tensão nos músculos anteriores da coxa. Essa inclinação, juntamente com a compressão exercida pelo peso do corpo sobre a coluna lombar, acentua a lordose nesse nível, que pode ser ainda mais acentuada por fatores como gravidez, obesidade e uso de sapatos de salto alto.

\section{Sentado}

É verdade que a postura sentada pode trazer vários prejuízos para a saúde se o posto de trabalho não for bem concebido. A postura sentada e imóvel, de acordo com a qualidade do apoio, pode provocar fadiga muscular lombar e compressão da massa muscular das coxas, que gera dores nos membros inferiores. O organismo adapta-se mal às perturbações provocadas pela posição sentada.

Da mesma forma que na postura em pé, há diferentes maneiras de estar sentado. De acordo com os estudos disponíveis, os efeitos não desejados podem ser evitados se o arranjo físico considera as necessidades reais para a operação realizada durante a posição sentada (Abrahão \& Assunção, 2002).

O ajuste da altura da cadeira pode influenciar o retorno venoso se houver compressão sobre a parte posterior das coxas. A pressão intradiscal é aumentada se comparada com a postura em pé, mas se o trabalhador puder variar a postura serão garantidas as trocas nutricionais necessárias aos discos.

De qualquer maneira, em relação à posição de pé, o trabalho cardiovascular é menos importante na situação de trabalho sentado. Nesta situação, a freqüência cardíaca e a pressão sangüínea são menos elevadas, o equilíbrio e a estabilidade são mais fáceis e a solicitação músculo-esquelética é menos importante.

A posição sentada confortável para a maioria das pessoas é aquela que mantém as articulações intervertebrais em algum ponto da amplitude média, permitindo liberdade de movimento e tendo os músculos anteriores e posteriores balanceados. Nesta posição, a tensão entre as superfícies das articulações apofisárias é menor do que na posição em pé e fica concentrada nas porções mediana e superior das articulações (Dunlop et al. 1984). Contudo, da mesma forma que para a posição de pé, mesmo uma posição sentada confortável não pode ser mantida por períodos prolongados por razões explicitadas mais adiante, sendo importante, assim, que o design do assento possibilite as mudanças na postura.

Desvios da amplitude média por períodos prolongados conduzem à sobrecarga nas articulações e nas estruturas ligamentares. Numa coluna normal, a posição sentada com uma postura encurvada pode levar ao hiperestiramento dos ligamentos intervertebrais e das fibras anulares posteriores, aumentando consideravelmente a pressão intradiscal, provocando, mais tarde, degeneração dos componentes do disco.

Como dito anteriormente, a pressão intradiscal é geralmente mais elevada na posição sentada sem apoio do que na posição em pé, o que ocorre, em grande parte, devido ao músculo psoas maior, que possui uma ação vigorosa como estabilizador da coluna lombar nessa posição ao mesmo tempo em que exerce um considerável efeito compressivo sobre a coluna. As alterações na lordose lombar são acompanhadas de aumento ou diminuição na pressão intradiscal, a depender da inclinação do assento ou do encosto e da altura do suporte lombar, da cadeira e da mesa. Em uma cadeira bem projetada, a pressão intradiscal pode ser inferior àquela observa- 
da na posição em pé (Oliver \& Middleditch, 1998). No entanto, as vantagens de um bom projeto de cadeira não autorizam uma análise que desconsidere todos os outros determinantes da postura. O ser humano, em situação de trabalho, coloca todo o seu corpo e a sua inteligência no projeto de sua ação para alcançar os objetivos pretendidos. A cadeirologia nega a inteligência da postura.

A postura sentada nem sempre é nociva. Os estudos cinematográficos mostram que se não há pressão temporal e se as exigências gestuais, posturais e visuais não são fortes, a imobilidade total desaparece, pois é possivel ao indivíduo melhorar a circulação sangüínea, solicitar diferentes músculos e outros órgãos de maneira alternativa.

Os resultados da análise ergonômica colocam em evidência que a postura adotada pelo trabalhador é multideterminada e não fruto de uma casualidade ou de idiossincrasias pessoais, nos termos utilizados por Lima (2000). Ou seja, ela é a maneira inteligente de a recepcionista organizar os seus segmentos corporais para controlar a mercadoria, evitar o erro, ser cortês com o cliente e acelerar o atendimento.

Diferentes posições implicam diferentes respostas musculares que são desejadas pelo trabalhador ao executar a sua tarefa. A distribuição das tensões na coluna depende da posição da carga transportada. Por exemplo, se uma carga é transportada no alto do dorso (trabalhadores que transportam saco de cimento sobre os ombros), o tronco compensa inclinando-se para a frente, de modo que o músculo eretor da coluna seja mais solicitado do que seria no caso da posição em pé sem transporte de carga. Se a carga é transportada abaixo do nível dos ombros, será o músculo psoas maior que vai sofrer maior contração, indicando que a carga está causando uma extensão da coluna vertebral (Oliver \& Middleditch, 1998).

Quando o centro de gravidade é deslocado para os lados, como é o caso quando se mantém um peso em uma das mãos, o eretor da coluna contralateral contrai-se para evitar inclinação lateral indesejada.

Essa dinâmica corporal é reproduzida pelas recepcionistas durante a realização de suas tarefas. O corpo, conhecendo as respostas musculares a diferentes posições nas quais uma carga pode ser transportada, elabora, em nível subconsciente, estratégias para repousar (e depois solicitar) grupos musculares quando eles começam a sofrer fadiga. Por isso é impossível manter uma mesma postura prolongadamente, mesmo que seja aquela considerada correta pela cadeirologia.

A manutenção de uma atitude determinada durante um período prolongado pode provocar diferentes tipos de problemas. $O$ que permite a adoção de uma postura específica é a atividade muscular dinâmica definindo os movimentos que permitem passar de uma postura a outra. Uma posição estereotipada é também a manifestação de uma má adaptação do trabalho ao indivíduo: organização da tarefa, dimensionamento do posto de trabalho, iluminação, cadência.

Uma postura pode ser, ao mesmo tempo, um problema particular e um sintoma de uma desordem mais profunda da organização do trabalho. Ou seja, a postura adotada não é produto do inteiro arbítrio do indivíduo, ela é determinada pelas características do contexto de trabalho, aí incluídas as dimensões do mobiliário e dos equipamentos, pressão temporal, estado de saúde do trabalhador.

A organização da postura participa na realização da tarefa e permite facilitar a sua execução e ganhar tempo. As tarefas solicitam a mobilização das capacidades músculo-esqueléticas, sensoriais, cognitivas e afetivas. As diversas dimensões do corpo humano são envolvidas durante a atividade de trabalho. Os resultados da análise ergonômica do trabalho permitem compreender aquilo que uma análise superficial nomeia de postura incorreta, que seria produto da escolha individual e, assim, passível de mudança por meio de treinamento. Ou seja, a abordagem das posturas adotadas no trabalho pode se beneficiar da análise ergonômica da atividade.

\section{Agradecimentos}

A autora agradece a leitura atenta e os comentários valiosos feitos por Dr. Carlos Alberto Diniz. 


\section{Referências Bibliográficas}

ABRAHÃO, J. I.; ASSUNÇÃO, A. A. A concepção de postos de trabalho informatizados visando à prevenção de problemas posturais. Ver. Saúde Col. UEFS, 1(1):38-45, 2002.

ABRAHÃO, J. I. Reestruturação produtiva e variabilidade do trabalho. Psico. Teo. Pesq. 16(1):49-54, 2000.

ASSUNÇÃO, A. A. De la déficience à la gestion collective du travail: les troubles musculo-squelettiques dans la restauration collective.1998 Thèse de Doctorat d'Ergonomie. Paris: École Pratique des Hautes Études.

Doenças osteoarticulares de origem profissional. In: PEDROSO, E. R. P \& ROCHA, M. O. C. (orgs.) Clínica Médica. 2 ed. São Paulo.; Atheneu [no prelo].

Gesto repetitivo, trabalho variável. In: SALIM, C. A.; \& CARVALHO, L. F. (orgs.). Saúde e Segurança no Trabalho: contextos e vertentes. Belo Horizonte: PRODAT/FUNDACENTRO, pp. 77-92, 2002.

O saber prático construído pela experiência compensa as deficiências provocadas pelas condições inadequadas de trabalho. Trabalho e Educação, 12(1):35-49, 2003.

O trabalho no caixa de um hipermercado: estudo ergonômico. Relatório de pesquisa. UFMG, Laboratório de Ergonomia, 129 p., 1999.

ASSUNÇÃO, A. A.; \& LIMA, F. P. A. Condições ergonômicas em uma fábrica de jóias. Relatório de pesquisa. UFMG, Laboratório de Ergonomia, 2000.

BIENFAIT, M. Os desequilíbrios estáticos. São Paulo: Summus editorial, 1993, $149 \mathrm{p}$.

BJELLE, A.; HAGBERG, M.; MICHAELSON, $G$. Occupational and individual factors in acute shoulder-neck disorders among industrial worker. Br. J. Ind. Med. 38:356363,1981 .
BONGERS, P. M.; KREMER, A. M.; \& ter LAAK, J. Are psychosocial factors, risk factors for symptoms and signs of the shoulder, elbow, or hand/wrist?: A review of the epidemiological literature. American Journal of Industrial Medicine 41:315-342, 2002.

CLAUDON, L.; \& CNOCKAERT, J. C. Biomécanique des tissus mous. Modèles biomécaniques $d$ 'analyse des contraintes au poste de travail dans le contexte des troubles musculosquelettiques. Doc. Méd. du Trav. 58:140-148,1994.

DINIZ, C. A.; \& FERREIRA Jr., M. Prevalência de sintomas músculo-esqueléticos em operadores de checkout em mercados. Rev. Bras. de Saúde Ocup. 25: 75-91, 1993/1994.

DOLAN, P.; ADAMS, M. A.; \& HUTTON, W. C. Commonly adopted postures and their effect on the lumbar spine. Spine, 13(2): 197, 1988.

DUNLOP, R. B.; ADAMS, M. A.; \&HUTTON, $W$. C. Disc space narrowing and the lumbar facet joints. J. Bone J. Surg. (Br.), 66-B, 706, 1984.

European Agency for Safety and Health at Work. Repetitive strain injuries in the Member States of the European Union: the resultats of information request. Luxembourg: Office for Official Publications of the European Communities, 2000.

HAGBERG, M. Work load and fatigue in repetitive arm elevations. Ergonomics, 24:543-555, 1981.

KENDALL, F. P.; MCCREARY, E. K.; \& Provance, P. G. Músculos: provas e funções. São Paulo: Manole, 1995, 453 p.

LAVILLE, A. Cadence de travail et posture. Le Travail Humain, 31(1-2):73-94, 1968.

Ergonomia. São Paulo: Pedagógica e Universitária, USP, 1977. 
LEONARD S. A. The role of exercise and posture in preventing low back injury. AAOHN Journal, 38(7):318-322, 1990.

LIMA, F. P. A. A ergonomia como instrumento de segurança e melhoria das condições de trabalho. Anais do I Seminário de Segurança do Trabalho e Ergonomia Florestal - ERGOFLOR. Belo Horizonte, junho de 2000.

OLIVER, J.; \& MIDDLEDITCH, A. Anatomia funcional da coluna vertebral. Rio de Janeiro: Revinter, 1998, 325 p.

RYAN, G. A. The prevalence of musculoskeletal symptoms in supermarket workers. Ergonomics, 32(4):359-371, 1989.

VÉZINA, N.; LABERGE, M.; \& LAJOIE, A. Debout, assis ou assis-debout?
Montréal: Formations CSST-IRSST, UQAM, 1998.

VÉZINA, N.; \& LAJOIE, N. Le siège assisdebout: une solution de rechange à la posture debout statique. Obje. Prev. 19(4):38-41, 1996.

WINKEL, J.; \& WESTGAARD, R. Occupational and individual risk factors for shoulderneck complaints. Part II. The scientific basis (literature review) for the guide. Int. J. Ind. Ergonomics, 10:85-104, 1992

WISNER, A. Componentes cognitivos e psíquicos da carga de trabalho. In:

Por dentro do trabalho: ergonomia, método e técnicas. São Paulo: FTD/Oboré, 1987.

WISNER A.; \& MARCELIN J. A quel homme le travail doit-il être adapté. Rapport n. 22. CNAM, Paris, 13 p. 1971. 